\title{
ADAPTIVE LIFTING BASED IMAGE COMPRESSION SCHEME USING INTERACTIVE ARTIFICIAL BEE COLONY ALGORITHM
}

\author{
Vrinda Shivashetty ${ }^{1}$ and G.G Rajput ${ }^{2}$ \\ ${ }^{1}$ Department of Computer Science, Gulbarga University Gulbarga, India \\ mbvrinda2004eyahoo.co.in \\ ${ }^{2}$ Department of Computer Science, \\ Rani Channamma University, Belagavi, India \\ ggrajputeyahoo.co.in
}

\begin{abstract}
This paper presents image compression method using Interactive Artificial Bee Colony (IABC) optimization algorithm. The proposed method reduces storage and facilitates data transmission by reducing transmission costs. To get the finest quality of compressed image, utilizing local search, IABC determines different update coefficient, and the best update coefficient is chosen optimally. By using local search in the update step, we alter the center pixels with the coefficient in 8-different directions with a considerable window size, to produce the compressed image, expressed in terms of both PSNR and compression ratio. The IABC brings in the idea of universal gravitation into the consideration of the affection between onlooker bees and the employed bees. By passing on different values of the control parameter, the universal gravitation involved in the IABC has various quantities of the single onlooker bee and employed bees. As a result when compared to existing methods, the proposed work gives better PSNR.
\end{abstract}

\section{KEYWORDS}

IABC, Image Compression, Wavelet Transform, Adaptive Lifting Scheme, PSNR.

\section{INTRODUCTION}

The wavelet coding method has been recognized as an efficient coding technique for lossy image compression. The wavelet transform decomposes a typical image data to a few coefficients with large magnitude and many coefficients with small magnitude. As most of the energy of the image concentrates on these coefficients with large magnitude, lossy compression systems just by using coefficients with large magnitude can realize the reconstructed image with good quality and high compression ratio. For wavelet transforms, Lifting scheme(LS) allows efficient construction of the filter banks. The restriction of this structure is that the filter structure is fixed over the entire signal. In many applications to shape itself to the signal it is very much desirable to design the filter banks. A number of such adaptive Lifting Schemes are proposed in the literature[12,14] which consider local characteristics of the signal for adapting. In this paper, image compression using IABC is proposed based on intelligent behavior of Honey bee swarms [8]. The paper is described as follows. In section II Compression techniques discussed, In section III a general lifting scheme is discussed and compared with the adaptive lifting scheme where the update step

David C. Wyld et al. (Eds) : CSITY, SIGPRO, DTMN - 2015

pp. 09-21, 2015. (C) CS \& IT-CSCP 2015

DOI : $10.5121 /$ csit.2015.50302 
is modified with the IABC algorithm. Section IV discusses about the proposed work. Section V explains the IABC algorithm and section VI describes the proposed algorithm.

\section{COMPRESSION TECHNIQUES}

The image compression techniques are generally classified into two categories depending whether or not an exact replica of the original image could be reconstructed using the compressed image. These are:

\section{Lossy technique}

2. Lossless technique

\section{Lossy Compression Techniques}

Lossy schemes provide much higher compression ratios than lossless schemes. Lossy schemes are widely used since the quality of the reconstructed images is adequate for most applications. By this scheme, the decompressed image is not identical to the original image, but reasonably close to it. The most popular current lossy image compression methods use a transform-based scheme.

\section{Lossless Compression Techniques}

In lossless compression techniques, the original image can be perfectly recovered from the compressed image. These are also called noiseless since they do not add noise to the signal. It is also known as entropy coding since it use decomposition techniques to minimize redundancy.

\section{LIFTING SCHEME}

Lifting scheme is used to implement critically sampled filter banks which have integer output. The lifting scheme can custom design the filters, essential in the transform algorithms. Independent of translating and dilating, needless of frequency analysis lifting scheme is processed into space domain. An answer to the algebraic stage of wavelet construction is provided by lifting scheme, which leads to a fast in-place calculation of the wavelet transform, i.e. it does not require auxiliary memory. Different wavelets show different image compression effect; the compressed image quality and the compression rate is not only relational to the filter length, but also concerns with regularity and local frequency, vanishing moment, orthogonality, biorthogonality. In this paper, we implement adaptive lifting scheme based upon wavelet decomposition. Then, with the help of IABC algorithm, we find the best directional window size to get better compression ratio with considerable quality.

\section{A. The Lifting Concept}

Lifting is a spatial (or time) domain construction of bi-orthogonal wavelets. The lifting scheme procedure consists of three steps: Split, Predict and Update (Fig. 1) and inverse Lifting scheme is shown in Fig. 2.

\section{Split:}

Split the original data into two disjoint subsets. Though any disjoint split is possible, in the standard lifting scheme we split the original data set $x[n]$ into the even indexed points, $x e[n]-$ $\mathrm{x}[2 \mathrm{n}]$, and the odd indexed points $\mathrm{xo}[\mathrm{n}]=\mathrm{x}[2 \mathrm{n}+1]$ 


\section{Predict:}

Generate the detail signals $d[n]$ as the predicting error using prediction operator $\mathrm{P}$

\section{Update:}

$$
\mathrm{d}[\mathrm{n}]=\mathrm{xo}[\mathrm{n}]-\mathrm{P}(\mathrm{xe}[\mathrm{n}])
$$

To obtain scaling coefficients $\mathrm{c}[\mathrm{n}]$ that represent a coarse approximation to the original signal $\mathrm{x}[\mathrm{n}]$ merge $\mathrm{xe}[\mathrm{n}]$ and $\mathrm{d}[\mathrm{n}]$. This is accomplished by applying an $\mathrm{U}$ update operator to the wavelet coefficients and adding to $\mathrm{xe}[\mathrm{n}]$.

$$
\mathrm{c}[\mathrm{n}]=\mathrm{xe}[\mathrm{n}]+\mathrm{U}(\mathrm{d}[\mathrm{n}])
$$

The above three steps is described as lifting stage. Iteration of the lifting stage on the output $\mathrm{c}[\mathrm{n}]$ creates the complete set of DWT scaling and wavelet coefficients $\mathrm{Cj}[\mathrm{n}]$ and $\mathrm{dj}[\mathrm{n}]$. At each step, we weight the $\mathrm{Cj}[\mathrm{n}]$ with ke and $\mathrm{dj}[\mathrm{n}]$ with ko respectively. The energy of the underlying scaling and wavelet functions is normalized.

The lifting stesp are inverted, even if $\mathrm{P}$ and $\mathrm{U}$ are nonlinear, non-invertible, or space-varyi.ng Rearranging (1) and (2), we have

$\mathrm{xe}[\mathrm{n}]=\mathrm{c}[\mathrm{n}]-\mathrm{U}(\mathrm{d}[\mathrm{n}])$,

$\mathrm{xo}[\mathrm{n}]=\mathrm{d}[\mathrm{n}]+\mathrm{P}(\mathrm{xe}[\mathrm{n}])$.

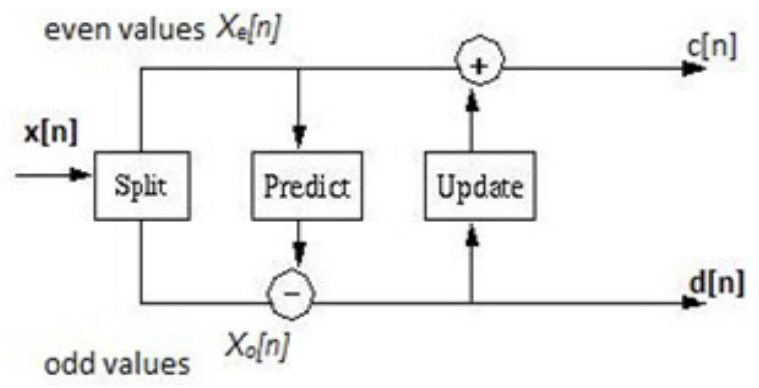

Fig.1. Lifting stage: Split, Predict, Update

As long as for the inverse and forward transforms $\mathrm{U}$ and $\mathrm{P}$ are chosen, the original signal will be perfectly reconstructed. The inverse lifting stage is shown in Fig.2.

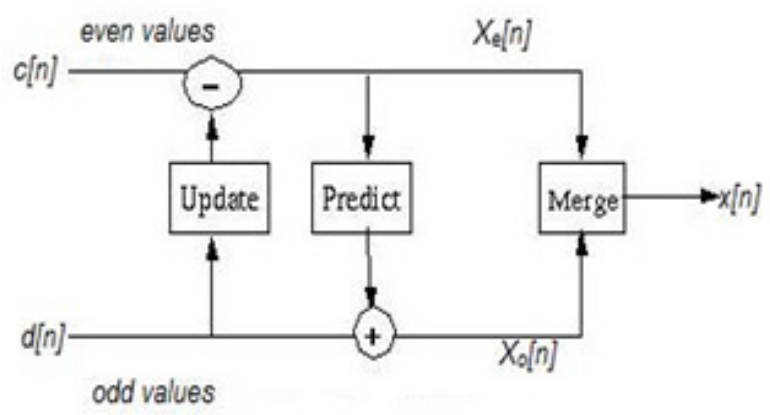

Fig.2. Inverse lifting steps: undo the Update, undo the Predict, and Merge the even and odd samples 


\section{B. Adaptive lifting scheme}

The adaptive lifting scheme is classical lifting modification . The Fig.3 shows the adaptive update lifting scheme followed by a fixed prediction. At each sample $\mathrm{n}$ According to a decision function $\mathrm{D}(\mathrm{x}[\mathrm{n}], \mathrm{y})$ an update operator is chosen. As in the classical and space-varying lifting, the critical point is that $\mathrm{D}(\mathrm{x}[\mathrm{n}], \mathrm{y})$ depends on $\mathrm{y}$, and it also depends on the sample being updated. The update operator and addition are fixed, in the standard lifting scheme. The choice of addition and the update operator depends on the information locally available within both the approximation signal and the detail signal in the adaptive lifting scheme.

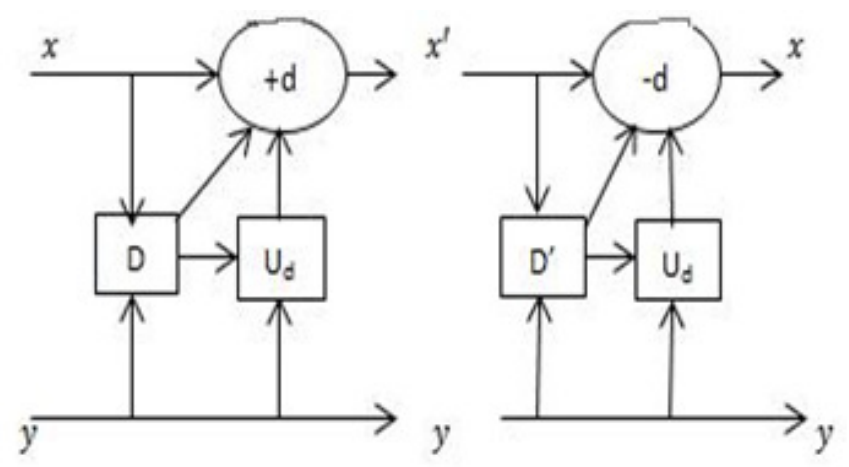

Fig.3. Adaptive update lifting scheme

According to the structure of lifting, Adaptive Lifting Scheme performs update first, and then performs prediction. Assume $\mathrm{x}=\mathrm{x}_{\mathrm{o}}(2 \mathrm{~m}, 2 \mathrm{n})$, where $\mathrm{x}_{\mathrm{o}}$ is the input image, which is split into two signal one is $\mathrm{x}$ average signal and y detail signal . The y detail signal includes $\mathrm{y}_{\mathrm{h}}$ horizontal signal , $\mathrm{y}_{\mathrm{v}}$ vertical signal, and $\mathrm{y}_{\mathrm{d}}$ diagonal signal.

The 2-D adaptive lifting formation is as follows:

Update: Coefficient $\mathrm{y}_{\mathrm{h}}, \mathrm{y}_{\mathrm{v},} \mathrm{y}_{\mathrm{d}}$ are used to update $\mathrm{x}$ :

$$
\mathrm{x}^{\prime}=\mathrm{U}\left(\mathrm{x}, \mathrm{y}_{\mathrm{h}}, \mathrm{y}_{\mathrm{v}}, \mathrm{y}_{\mathrm{d}}\right)
$$

Here, $\mathrm{U}$ is update operator, in which coefficients are chosen by $\mathrm{D}$ decidable factor.

Prediction: Updated low-frequency Coefficient $\mathrm{x}^{\prime}$ is used to predict $\mathrm{y}_{\mathrm{h}}, \mathrm{y}_{\mathrm{v}, \mathrm{y}_{\mathrm{d}}}$ :

$$
\begin{gathered}
y_{\mathrm{h}}{ }^{\prime}=\mathrm{y}_{\mathrm{h}}-\mathrm{p}_{\mathrm{h}}\left(\mathrm{x}, \mathrm{y}_{\mathrm{v}}, \mathrm{y}_{\mathrm{d}}\right) \\
\mathrm{y}_{\mathrm{v}}=\mathrm{y}_{\mathrm{v}}-\mathrm{p}_{\mathrm{v}}\left(\mathrm{x}-\mathrm{y}_{\mathrm{d}}\right) \\
\mathrm{y}_{\mathrm{d}}=\mathrm{y}_{\mathrm{d}}-\mathrm{p}_{\mathrm{d}}\left(\mathrm{x}^{\prime}\right)
\end{gathered}
$$

The $\mathrm{p}_{\mathrm{h}}, \mathrm{p}_{\mathrm{v}}, \mathrm{p}_{\mathrm{d}}$, are prediction schemes for different frequency bands. According to the local feature adjacent to $\mathrm{x}, \mathrm{y}_{\mathrm{h}}, \mathrm{y}_{\mathrm{v}}$, and $\mathrm{y}_{\mathrm{d}}$ the scheme adaptively chooses $\mathrm{U}$ update operator and $\mathrm{P}$ prediction operator. Without recording any overhead information. the perfect reconstruction is ensured by the update and prediction scheme The choice of $U$ update operator and the addition operator $\oplus$ in adaptive lifting scheme depends on the information locally available in the $\mathrm{x}$ approximation signal and the y detail signal. In reality, this choice will be triggered by the so called decision map $\mathrm{D}: \mathrm{X} \times \mathrm{Y} \rightarrow \mathrm{D}^{\mathrm{Z}}$ where $\mathrm{D}$ is the decision set. We have a different $\mathrm{U}_{\mathrm{d}}$ update operator and addition $\bigoplus_{\mathrm{d}}$ for every possible decision $\mathrm{d} C \mathrm{D}$ of the decision map. Thus the analysis step is given as 
follows,

$$
x(n)=x(n) \oplus_{\mathrm{d}_{n}} \mathrm{U}_{\mathrm{d}_{n}}(\mathrm{y})(\mathrm{n})
$$

At location $\mathrm{n} \mathrm{d}_{\mathrm{n}}=\mathrm{D}(\mathrm{x}, \mathrm{y})(\mathrm{n})$ is the decision. Assuming that the reversibility condition $\bigoplus_{\mathrm{d}}$ holds for every possible decision $\mathrm{d} \in \mathrm{D}$ and it is given by

$$
x(n)=x^{\prime}(n) \ominus_{d_{n}} U_{d_{n}}(y)(n)
$$

where $\Theta_{\mathrm{dn}}$ denotes the subtraction that inverts $\bigoplus_{\mathrm{d}}$.

The decision $d_{n}=D(x, y)(n)$ depends on the $x$ original signal. On the other hand, during synthesis, we do not know but "only" its update $x^{\prime}$. In general, this prohibits the $\mathrm{d}_{\mathrm{n}}$ computation and in such cases, perfect reconstruction is out of reach. However, it is still possible to recover $d_{n}$ as there exist a number of situations from an posterior decision map.

\section{PROPOSED BLOCK DIAGRAM}

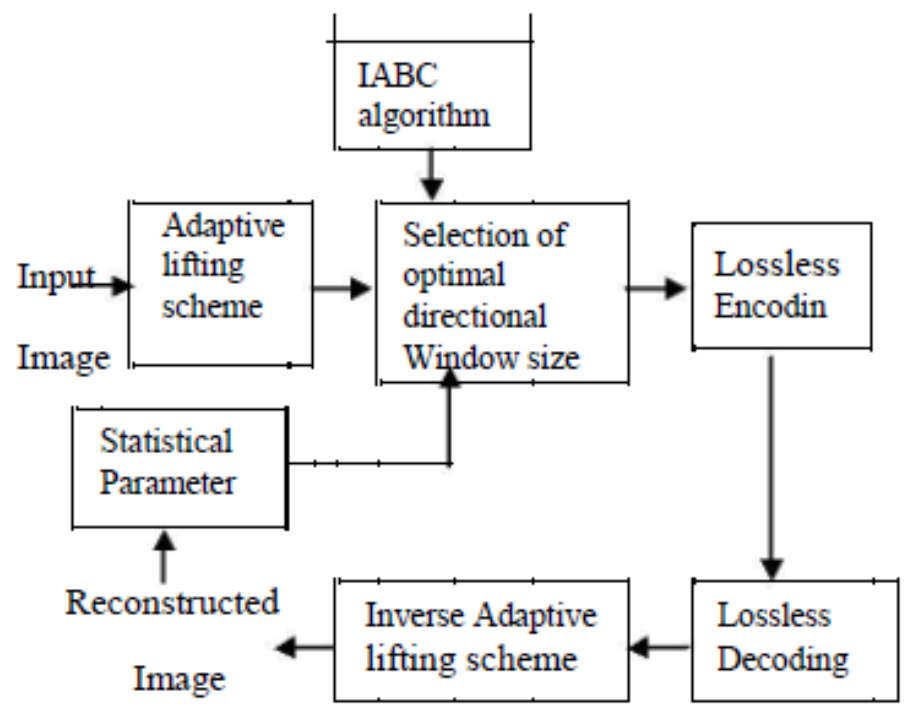

Fig. 4. Proposed Block diagram

In this method it is observed that, wavelet transform did not yield better quality for more detail texture image, so it gives a way for adaptive lifting scheme based decomposition. To determine the best directional window size and to produce the better quality for more detail texture image by local search process an Interactive Artificial Bee Colony algorithm, recent and successful optimization tool, is used. The lossless encoding technique is used to get a perfect compressed image. After the encoding process, data will be in digital form so that one can store or transmit the data to the long distance. For compressed data the image is reconstructed by applying decoding process followed by Inverse adaptive lifting scheme.

\section{A. Need for Interactive Artificial Bee Colony algorithm}

Choosing a global update coefficient does not give better compression ratio and quality. Interactive Artificial Bee Colony Algorithm by local search finds different update coefficient and helps to determine the best update coefficient optimally to get best quality of compressed image. 
In update step, the center pixels are modified with the co-efficient in 8-different direction with a considerable window size and by using local search algorithm. To determine best directional window with an considerable size an IABC algorithm is used.

\section{INTERACTIVE ARTIFICIAL BEE COLONY ALgORITHM}

The most recently defined algorithm, motivated by the intelligent behavior of honey bees is Interactive Artificial Bee Colony Algorithm. It is as simple as Artificial Bee Colony Algorithm and differential Evolution(DE) algorithms Particle Swarm Optimization, and uses common control parameters such as maximum cycle number and colony size. As an optimization tool, IABC provides a population-based search procedure in which artificial bees with the time modifies the individuals called food positions and the aim of bee's is to discover the food sources placed with high nectar amount and at last the one with highest nectar.

In IABC algorithm, the solution space randomly spray percentage of the populations, fitness values called as nectar amounts is calculated, represents the ratio of employed bees to the total population. When these populations are positioned into the solution space they are called employee bees. The probability of selecting a food source is then calculated, select a food source to move by roulette wheel selection for every onlooker bees and then nectar amounts of them is determined. If the employed bees fitness values does not improve by predetermined number of iterations continuously, called "LIMIT", such food sources are abandoned, and these employed bees become the scouts. The scouts are moved. The position and the best fitness value found by the bees is memorized. We check whether the termination condition is satisfied by the total number of iterations. If the condition for termination is satisfied, terminate the program and output the results. The flow chart for IABC is shown in Fig. 5.

The process of the IABC can be described in 6 steps:

Step 1. Initialization phase:

In Initialization phase within the maximum boundaries of each pixels an window size is chosen

area $=1+$ floor $($ maxarea*rand $(1))$;

row $=5+$ floor(r*rand(1));

$\mathrm{col}=5+$ floor $(\mathrm{c} * \operatorname{rand}(1))$;

Step 2. Employed bees phase

In Employed bees phase of the algorithm, a local search xi, is conducted in the neighbourhood of each directional window, defined by using:

$\mathrm{a} 1=\mathrm{img}$ (row-area, col-area);

b1=img(row,col-area);

c1=img(row+area,col-area);

$\mathrm{d} 1=\mathrm{img}($ row+area,col+area) 


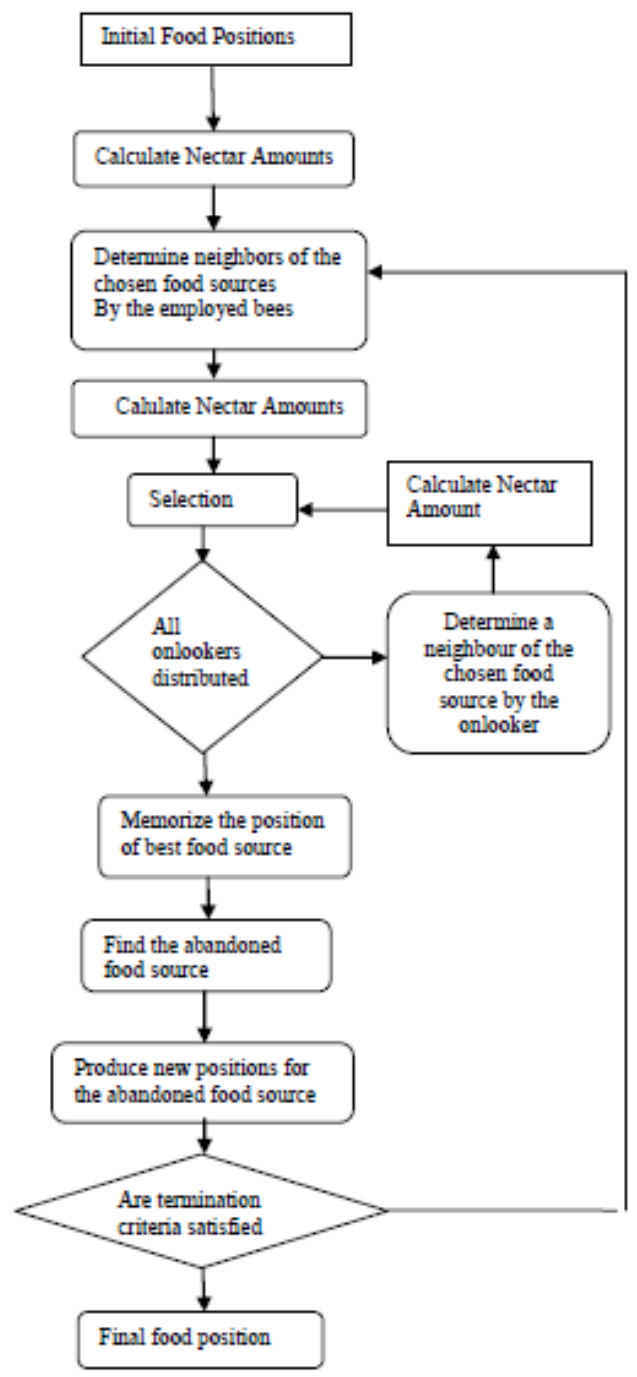

Fig. 5. Flow chart for IABC Algorithm

If we get fitness better than before, then memorize the current one.

\section{If(localPSNR $>$ prevPSNR)}

prevPSNR=localPSNR;

bestimg=recconstimg;

After generating a new neighbour solution by local search, the new solution fitness (quality) is evaluated and better one is kept in the population. Now the counter is incremented for each local search up to 8 level.

Step 3. Onlooker bees phase:

In Onlooker bees phase of the algorithm, the probability of selecting a food source is calculated by using equation 
$P_{i}=\frac{F\left(\theta_{i}\right)}{\sum_{k=1}^{S} F\left(\theta_{k}\right)}$

( ), is the employed bee fitness value that is picked by applying the roulette wheel selection.

$P_{i}$ is the probability of selecting the ${ }^{\text {th }}$ employed bee. ( ) randomly selected employed bee fitness value

By roulette wheel selection, select a food source to move for every onlooker bees and then the nectar amounts is determined. The onlookers movement follows the below equation

$x_{i j}(t+1)=\theta_{i j}(t)+\sum_{k=1}^{n} \tilde{F}_{i k j} \cdot\left[\theta_{i j}(t)-\theta_{k j}(t)\right]$

Step 4. Scout bees' phase

In the Scout bees' phase If the employed bees fitness values does not improve by predetermined number of iterations continuously, called "LIMIT", such food sources are abandoned, and these employed bees become the scouts. The scouts are moved by the equation

$\theta_{i j}=\theta_{i j \min }+r \cdot\left(\theta_{i j \max }-\theta_{i j \min }\right)$

Step 5. Update the Best Food Source found so far:

In this step the best fitness value and the position is memorized, which are found by the bees.

Step 6. Termination Checking:

In this step check whether the termination condition is satisfied by the total number of iterations. If the condition for termination is satisfied, terminate the program and output the results.; otherwise go back to the Step 3.

\section{PROPOSED ALgORITHM}

In the proposed method, the input image is decomposed using wavelet lifting scheme and then the Interactive artificial bee colony algorithm is used in the update process to get considerable quality.

\section{A. Algorithm steps:}

Step 1: Input the Gray scale Image.

Step 2: split the image into odd and even pixel regions.

Step 3: Decompose the image as (odd-even) for next prediction step.

Step 4: Fix the maximum coverage size as ' $M$ ' and initialized

' $\mathrm{K}=0$ ' for prediction co-efficient. Where $\mathrm{M}$ is maximum window size, upto which it will do local search for each center pixels maximum window size in our program is 5 . 
Step 5: Each pixel in the decomposed image is Scanned and its present fitness value and compression ratio is calculated.

Step 6: To predict ' $a$ ' and ' $b$ ' call direction finding algorithm co-efficient of all 8-direction combination. The 8- direction combinations are a1,b1,c1,d1,a2,b2,c2,d2

\begin{tabular}{|l|l|l|l|l|l|}
\hline & DL & & VT & DR & \\
\hline & & DL & VT & & \\
\hline HL & HL & HL & X & HR & HR \\
\hline & DD & DD & VD & DB & \\
\hline DD & & & VD & & DB \\
\hline
\end{tabular}

Fig.6. Directional coefficient for center pixel ' $\mathrm{x}$ '

Where $\mathrm{x}$ is an center pixel to be update

HL is predicted coefficient in horizontal left direction

HR is predicted coefficient in horizontal right direction

VT is predicted coefficient in vertically top direction

VD is predicted coefficient in vertically down direction

DL is predicted coefficient in diagonally top left direction

DR is predicted coefficient in diagonally top right direction

DB is predicted coefficient in diagonally bottom left direction

DD is predicted coefficient in diagonally bottom right direction

Step 7: By using Update lifting formula for each direction prediction calculate update weight and find compression ratio and PSNR.

The Peak Signal to Noise Ratio(PSNR) represents a measure of the peak error and is expressed in decibels. PSNR is defined by

$P S N R=10 . \log \_10\left(\frac{255^{2}}{M S E}\right)$

Step 8: The best individual is memorized, CR and its direction using IABC local search.

Step 9: To predict and update the best value for different range of window size iterate $\mathrm{K}$ from (0 to $\mathrm{M})$.

Step 10: Using IABC local search, memorize the best window size in terms of its MSE and CR for each reference pixel.

\section{EXPERIMENTAL RESULTS}

The proposed algorithm is tested on standard images with different image formats. The Reconstructed images are shown in figure 7. The results are tabulated for various images in Table(1).Lena image is a JPEG image and the results obtained is better than existing methods. 

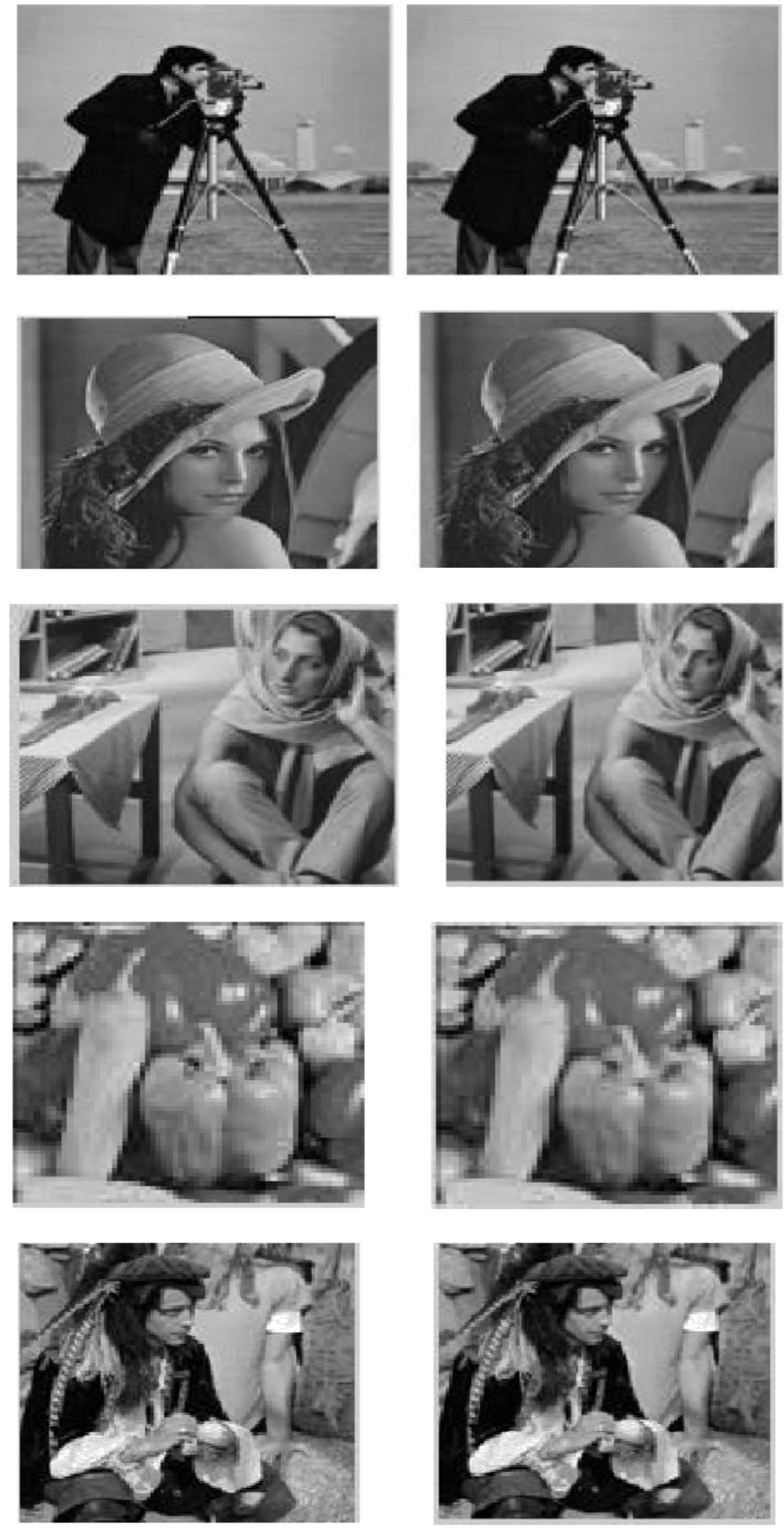

Fig. 7. Reconstructed Images with lifting with IABC (a) Original Image (b) Output of lifting scheme with IABC. 
Table 1: Comparison table for cameraman image

\begin{tabular}{|c|c|c|c|c|c|}
\hline \multirow{3}{*}{$\begin{array}{c}\text { Compression } \\
\text { Ratio }\end{array}$} & \multicolumn{5}{|c|}{$\begin{array}{c}\text { PSNR fro different images obtained using Lifting } \\
\text { Scheme using IABC }\end{array}$} \\
\cline { 2 - 6 } & $\begin{array}{l}\text { Cameraman } \\
\text { Image }\end{array}$ & $\begin{array}{l}\text { Lena } \\
\text { Image }\end{array}$ & $\begin{array}{l}\text { Barbara } \\
\text { Image }\end{array}$ & $\begin{array}{c}\text { Pepper } \\
\text { Image }\end{array}$ & $\begin{array}{l}\text { Rice } \\
\text { Image }\end{array}$ \\
\hline 30 & 41.78 & 43.4 & 42.39 & 40.83 & 40.27 \\
\hline 40 & 38.92 & 39.4 & 38.95 & 38.10 & 37.82 \\
\hline 50 & 38.63 & 38.2 & 38.31 & 37.85 & 36.74 \\
\hline 60 & 34.26 & 33.9 & 33.78 & 34.57 & 33.74 \\
\hline
\end{tabular}

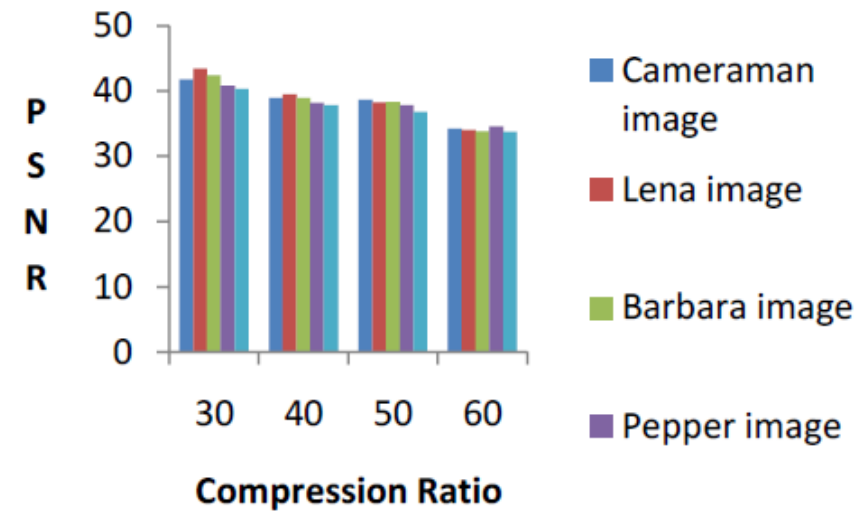

Fig. 8: Graph representing CR Vs PSNR for different images.

\section{CONCLUSION AND FUTURE ENHANCEMENTS}

In this paper, a method to optimize the prediction function used in lifting scheme using IABC algorithm for image compression is proposed. IABC algorithm is implemented in update process of lifting scheme to give better PSNR. From the experimental results, it is concluded that proposed method yields improved quality compare to existing methods in the literature. The proposed method gives the way to reduce the data to represent the image and thereby decreases transmission bandwidth. Hence, the transmission cost and memory cost is reduced.

In future work, Interactive Artificial Bee Colony algorithm shall be implemented in the thresholding process to reduce the number of coefficient representing the image by optimally choosing the thresholding value to get more better compression and quality. 


\section{REFERENCES}

[1] Subramanya A. "Image Compression Technique, " potentials IEEE, Vol. 20, issue 1,pp19-23, FebMarch 2001.

[2] Rafael C. Gonzalez, Richard Eugene; " Digital image processing”, Edition 3, 2008,page 466.

[3] W. Sweldens, "The lifting scheme: A new philosophy in biorthogonal wavelet constructions", in Proc. SPIE, vol. 2569,1995,pp. 68-79.

[4] W. Sweldens, "The lifting scheme: A construction of second-generation wavelets", SIAM J. Math. Anal., vol. 29, no. 2, pp. 511-546,1997.

[5] A.R. Calderbank, I Daubechies, W. Sweldens, and B-L Yeo, "Wavelet transforms that map integers to integers", J. Appl. Comput. Harmon, Anal., vol.5, no. 3, 1998.

[6] M. Adams and F. Kossentini, "Reversible Integer-to-Integer Wavelet Transforms for Image Compression: Performance Evaluation and Analysis", IEEE Trans.On Image Processing, vol.9, no.6, pp. 1010-1024, Jun 2000.

[7] N.V Boulgouris, D. Tzovaras, and M.G. Strintzis, "Lossless image compression based on optimal prediction, adaptive lifting, and conditional arithmetic coding", IEEE, Trans. Image Process., vol. 10, no. 1,pp. 1-14, Jan. 2001.

[8] Pei-Wei Tsai, Jeng-Shyang Pan, Bin-Yih Liao, and Shu- Chuan Chu," Enhanced Artificial Bee Colony Optimization", International Journal of Innovative Computing, Information and control, vol.5, no.12, pp.1-12, Dec. 2009.

[9] J. Kennedy, R.C. Eberhart, and Y.Shi, "Swarm Intelligence", Morgan Kaufmann Publishers, San Francisco,2001.

[10] B. Akay and D. Karaboga, "Parameter tuning for the artificial bee colony algorithm," ICCCI 2009 (R.Kowalezyk, N.T. Nguyen and S.M.Chen,eds.), LNAI, vol. 5796, 2009, pp. 608-619.

[11] V. U Kale and N.N. Khalsa, "Performance evaluation of various wavelets for image compression of natural and artificial images", International Journal of Computer Science and communication 1(2010), no.1, pp. 179-184.

[12] D. Karaboga and B. Akay, A survey: "Algorithms simulating bee swarm intelligence", Artificial Intelligence Review 31(2009), no. 1, pp. 55-68.

[13] G. Piella and H.J.A.M. Heijmans, "Adaptive lifting schemes with perfect reconstruction”, Research Report PNARO104,CWI, Amsterdam, Feb. 2001.

[14] F.W. Moore, "A genetic algorithm for optimized reconstruction of quantized signals", Evolutionary computation, 2005. The 2005 IEEE congress on, vol. 1,2005, pp. 105-111.

[15] R. Ramanathan, K. Kalaiarasi, D. Prabha, "Improved wavelet based compression with adaptivelifting scheme using Artificial Bee Colony algorithm", International Journal of Advanced Research in Computer Engineering \& Technology, Vol 2 , Issue 4, April 2013.

[16] W. Trappe and K.J.R.Liu, "Adaptivity in the lifting scheme," in 33th Conference on Information science and systems, Baltimore, March 1999, pp. 950-958.

[17] D. Karaboga, “ An Idea Based On Honey Bee Swarm For Numerical Optimization”, Technical Report-TR06, Erciyes University, Engineering Faculty, Computer Engineering Department, 2005.

[18] E. Bonabeau, M. Dorigo, and G. Theraulaz, "Swarm Intelligence: From Natural to Artificial Intelligence", NY: Oxford University Press, 1999.

[19] P.-W. Tsai, J.-S. Pan, S.-M. Chen, B. -Y. Liao, and S.-P. Hao, "Parallel Cat Swarm Optimization”, Proc. Of 7th International Conference on Machine Learning and Cybernetics, pp. 3328-3333, Kunming, China, 2008.

[20] Y. Guo, X.Gao, H. Yin, and Z. Tang, "Coevolutionary Optimization Algorithm with Dynamic Sub-population Size", International Journal of Innovative Computing, Information and Control, vol.3, no.2, pp.435-448, 2007.

[21] M. Dorigo and L.M. Gambardella, "Ant Colony Optimization for Data Clustering", Proc. Of 8th Pacific Rim International Conference on Artificial Intelligence, Auckland, New Zealand, LNAI 3157, pp. 534-543,2004. 


\section{AUTHOR PROFILE}

Vrinda Shiva Shetty received B.E from Gurbarga University and M.Tech degree from VTU in Computer Science and Engineering and presently pursuing Ph.D in Image Compression from the University of Gulbarga University, Gulbarga, and Karnataka. Field of Interest includes Intelligent Image Processing, Evolutionary Computation.

Dr. G. G. Rajput currently working as Associate Professor in the Department of Computer Science at Rani Channamma University Belagavi, Karnataka State, India. The Area of interest includes Image processing, Pattern recognition, Operations Research and Software Engineering. 